\title{
Surpresas do naturalismo luso-brasileiro: Bom Crioulo, de Adolfo Caminha, e O Baráo de Lavos, de Abel Botelho ${ }^{1}$
}

Horácio Costa

Universidade de São Paulo

A Hélio Bélik, in memoriam

RESUMO: OS ROMANCES BOM CRIOULO E O BARÃO DE LAVOS, ESCRITOS AO FINAL DO PERÍODO DE VIGÊNCIA DO NATURALISMO NO BRASIL E EM PORTUGAL, LIDAM COM UM TEMA TABU À ÉPOCA DE SUA ESCRITURA: A HOMOSSEXUALIDADE. O LEVANTAMENTO DE SUAS DIFERENÇAS NA APROXIMAÇÃO A ESSE TEMA, BEM COMO DAS RESPOSTAS DA CRÍTICA LITERÁRIA QUE SE OCUPOU DESSAS OBRAS NO BRASIL NO SÉCULO PASSADO, É O TEMA DO PRESENTE ENSAIO, QUE TERMINA POR CONSIDERAR AS RAZÕES DA NÃO-INCLUSÃO DELAS, ESPECIALMENTE DA PRIMEIRA, NO CÂNONE LITERÁRIO VIGENTE.

\section{ABSTRACT: THE NOVELS BOM CRIOULO AND O BARÃO DE LAVOS, WRITTEN AT THE TWILIGHT OF NATURALISM IN BRAZIL AND IN PORTUGAL, DEAL WITH A TABOO AT THE TIME OF THEIR PUBLICATION: HOMOSEXUALITY. THE CONTRAST OF THE WAYS BOTH WORKS DEALT WITH IT, AND THE RESPONSES OF THE CRITICAL INTELLIGENCE WHICH FOCUSED THEM IN BRAZIL, ARE THE CORE OF THE PRESENT ESSAY, WHICH ENDS UP BY CONSIDERING THE REASONS THAT COUNT FOR THEIR NON-INCLUSION - PARTI- CULARLY IN RELATION TO BOM CRIOULO - IN THE MODERN LITERARY CANON.}

PALAVRAS-CHAVE: ROMANCE BRASILEIRO E PORTUGUÊS - LITERATURA HOMOERÓTICA - HISTÓRIA DA CRÍTICA LITERÁRIA - CÂNONE LITERÁRIO KEY-WORDS: BRAZILIAN AND PORTUGUESE NOVEL - HOMOEROTIC LITERATURE - HISTORY OF LITERARY CRITICISM - LITERARY CANON

1 Publicado originalmente em espanhol na revista Biblioteca de México n. 32, março/abril de 1996, págs. 45-49. 
m 1895, o jovem escritor Adolfo Caminha, ex-oficial da Marinha Imperial Brasileira, nascido na província do Ceará, publicava no Rio de Janeiro um romance que não chamou a atenção que teria merecido, Bom Crioulo. Tanto no tema - a homossexualidade - como no enredo - a história da paixão entre um negro ex-escravo, o marinheiro Amaro, e um grumete branco, Aleixo, originário de Santa Catarina -, esse romance surpreende até hoje, devido à sua taxativa singularidade no âmbito da prosa escrita no século XIX, dentro ou fora do contexto brasileiro. Ainda, a surpresa do leitor tende a aumentar quando, ao longo de sua leitura, ele ou ela se dá conta da forma isenta com a qual Caminha desenvolve o romance - sempre tomando como referência o discurso do naturalismo internacional, no qual estilística e ideologicamente insere-se a escritura de Bom Crioulo - referindo-se à relação que vincula Amaro a Aleixo não em termos de excepcionalidade ou morbidade, o que seria de esperar considerando os preconceitos vigentes no período e os esquemas analíticos do naturalismo, mas como o relato objetivo - cru, seria quiçá o termo mais apropriado - de uma possível forma de amor, por mais turbulento e dramático que seja o seu final.

Quatro anos antes, em 1891, o romancista português Abel Botelho publicava em Lisboa O Barão de Lavos, primeira obra do ciclo chamado "A Patologia Social", que constaria de cinco romances, o último dos quais aparecido já em 1910. O Barão de Lavos, cujo enredo é centrado ao redor da pedofilia de um aristocrata português, utiliza-se desta para metaforizar a decadência das velhas classes poderosas de Portugal - o que, justamente, define o tema do romance. Assim como Amaro apaixona-se por Aleixo, D. Sebastião Pires de Castro e Noronha, o Barão de Lavos, apaixona-se por Eugénio, uma cria da rua, membro inato do bas-fond lisboeta. Segunda surpresa: no contexto de uma literatura basicamente fechada a derivas temáticas de exploração da sexualidade, como a lusitana - ainda que um Eça de Queirós, por exemplo, tivesse se encarregado de atacar o tradicional decoro português desde muitas frentes -, a precocidade na publicação de O Barão de Lavos rompe, timidamente que fosse, o tabu vinculado até então ao homoerotismo. Sem dúvida, esse romance, em virtude disso, converte-se em antecedente, na literatura portuguesa, desse tema.

Por exemplo, ainda que como uma espécie de predecessor "pela via negativa”, para dizê-lo assim, poder-se-ia afirmar que O Barão de Lavos ajudou 
a preparar o terreno para a polêmica criada em função do opúsculo Sodoma divinizada, de Raul Leal, já nos anos 1920, no contexto do modernismo, da qual Fernando Pessoa foi um dos protagonistas (claro está, em favor de Leal), polêmica que marcou, como um importante feito, a postura ética de toda uma geração de escritores em face do conceito da liberdade de expressão. ${ }^{2}$

Contudo, notáveis diferenças separam o romance brasileiro do português. A primeira delas aponta a natureza diferente dos autores em ambos. Se o enfoque sobre o amor em Bom Crioulo tende a ser objetivo, como acabo de mencionar, a relação entre o Barão e Eugénio revela, assim como expressa o nome do ciclo do qual O Barão de Lavos é parte, um "autor-patólogo", que carrega de terminologia "científica" e morbidade suas caracterizações e descrições, um tipo de autor muito mais próximo do mito, para assim chamá-lo, do romancista do naturalismo.

Nesse sentido, Massaud Moysés, crítico brasileiro que se ocupou da obra de Botelho, vê em O Barão de Lavos uma crítica em relação à dissolução da família em Portugal, nos seguintes termos: "A histeria e o homossexualismo, doenças individuais, traduzem o desgaste geral e se transformam em denunciadores de doenças coletivas; no caso, sobretudo, da família" (MOYSÉS, 1961: 30).

Deixemos por enquanto de lado essa visão irreflexiva, que leva o crítico a igualar uma pretensa doença, radicada no universo conceitual da segunda metade do século XIX, com uma condição da sexualidade humana, a atração sexual intergenérica. Voltando ao nosso eixo analítico, frisemos que, se Caminha narra uma história não-generalizável, e exatamente dessa singularidade faz nascer a força de suas personagens e de sua narração, Botelho utiliza a sua - e as suas - em função de sua análise da crise dos valores morais da sociedade, muito de acordo com o preconizado pela ética-estética real-naturalista; em virtude disso, o degenerado Barão de Lavos, sua histérica baronesa de origens burguesas e o malandro Eugénio, que de favorito do primeiro torna-se amante e explorador da segunda, dificilmente resistem a uma leitura atual, que se processe fora da arqueologia literária, isto é, uma leitura feita em função da literariedade mesma da obra.

\footnotetext{
2 Veja-se Sodoma Divinizada - uma polémica iniciada por Fernando Pessoa a propósito de António Botto, e também por ele terminada, com a ajuda de Álvaro Maia e Pedro Teotónio Pereira (da Liga da Acção dos Estudantes de Lisboa). Organização, introdução e cronologia de Aníbal Fernandes (Lisboa: Hiena, 1989).
} 
Comparando o escritor português com o brasileiro em termos autorais, a margem de autonomia deste em relação à ética-estética do naturalismo tornase óbvia em relação àquele. Se Abel Botelho parece um epígono de Zola, o esforço de Adolfo Caminha parece pender no sentido contrário, isto é, no de encontrar uma via própria para expressar-se em termos literários. Ainda assim, não foi senão recentemente que Bom Crioulo passou a despertar a atenção devida do público e da crítica. Isso pode ser explicado por dois motivos: um primordialmente estético e outro primordialmente ideológico.

O mapeamento dessas razões, e a discussão que tal possa gerar, ocupará o remanescente do presente ensaio.

Até há relativamente pouco, a crítica de corte mais acadêmico que se ocupou de Bom Crioulo repetiu o primeiro desses possíveis motivos, isto é, o de horizonte estético, como o responsável pela dificuldade na recepção do romance no Brasil de finais do século XIX. Por exemplo, Lúcia Miguel Pereira, influente crítica literária, ativa entre as décadas de 1940 e 1950 e que será mais de uma vez citada aqui, em seu Prosa de Ficção no Brasil de 1870 a 1920, ao passo de chamar a Caminha "uma das mais sérias vocações de romancista que já surgiram" nas letras brasileiras, estabelece que "é provável que, escrevendo quando já começava a debilitar-se a voga do naturalismo, seus livros tivessem sido recebidos com o cansaço que não poderia deixar de causar a monotonia dos processos literários que se estavam repetindo desde a estréia literária de Aluísio Azevedo" (MIGUEL PEREIRA, 1950: 164 e ss.) como a origem da misteriosa obnubilação da obra de Caminha entre seus contemporâneos. Além disso, faz referência também a outro fator para que tal sucedesse: Caminha teria sido dono de um temperamento "agressivo" e "amargo" - utilizo a caracterização de Miguel-Pereira -, o que lhe teria valido a indiferença do meio literário e, infere-se, dos mais estabelecidos críticos do Brasil de então, como o quase sempre atento José Veríssimo, "pai” da moderna crítica literária brasileira, e Sílvio Romero, que, como assinala Miguel-Pereira, só de passagem o menciona. É verdade que, por outro lado, a crítica carioca rende tributo à qualidade literária de Bom Crioulo em mais de um momento, por exemplo, dizendo que "esse livro, ousado na concepção e na execução, forte e dramático, humano e verdadeiro, é [...] com O Cortiço, o ponto alto do naturalismo", avançando um precioso juízo sobre o seu protagonista: "o tipo de Amaro [...] é dos melhor realizados da ficção brasileira”. Além disso, Miguel- 
Pereira não se equivocou ao assinalar que fora a "indigestão" do naturalismo o que impedira aos contemporâneos de Caminha ver no autor de Bom Crioulo alguém que "embora [...] se servisse de métodos já muito explorados, fazia-o com maior desembaraço e nitidez que a maior parte de seus predecessores; que não sofria do pedantismo nem da prolixidade que infirmam tantos livros da época".

Seja como for, a primeira opinião mencionada da crítica carioca não difere da de Araripe Júnior, contemporâneo de Caminha, que, sobre seu primeiro romance, A Normalista, publicado dois anos antes de Bom Crioulo, dizia que "tinha encontrado a escola a que se filiou já no declínio" e que $A$ Normalista "teria conhecido um sucesso extraordinário cinco ou seis anos atrás" (MIGUEL PEREIRA, 1950: 165), isto é, ainda na década de 1880, sob a égide do naturalismo internacional, cujo introdutor no Brasil foi o já mencionado Aluísio Azevedo (como é consabido, com O Mulato, em 1881). Sendo assim, tanto Miguel-Pereira como Araripe Júnior, mesmo que distantes cinco ou mais décadas no tempo, afirmam que foi a utilização de uma vertente literária ultrapassada o que afetou a recepção de Caminha no contexto da literatura brasileira no momento de sua publicação. Em poucas palavras, a Caminha imputou-se, por décadas, o que a leitura de Abel Botelho revela a qualquer leitor minimamente familiarizado com a ética-estética naturalista, isto é, o que poderíamos classificar de "epigonalidade" - o ser o epígono de uma corrente literária tida e havida como fora de moda -, como o seu maior defeito.

Entretanto, sabemo-lo todos, esse ponto de vista não se pode sustentar criticamente: o fato de que uma obra tenha como parti pris literário uma corrente que se convenciona chamar de ultrapassada não a impede de se desenvolver como fato literário com qualidade própria. Especialmente a partir de uma perspectiva pós-moderna, isso pode inclusive ser considerado como uma vantagem: alguns dos maiores escritores vivos da língua portuguesa, e para ficar só nela, justamente caracterizam-se pela nonchalance com que se posicionam diante de vogas literárias, e disso tiram um grande partido; tal é o caso de José Saramago, em cuja obra a presença do naturalismo está presente desde a primeira hora, como tive a oportunidade de enfocar em outro estudo. ${ }^{3}$

3 Cf. COSTA, Horácio. José Saramago: o período formativo. Lisboa: Caminho, 1997; México. D. F., Fondo de Cultura Económica, 2004 (trad. ao espanhol de Fátima Andreu). 
Mas regressemos à questão da recepção crítica da obra de Adolfo Caminha. Alfredo Bosi, escrevendo já nos anos 1970, sustenta uma postura diferente, porém não essencialmente oposta, da “epigonalista" que acabamos de conferir. Em sua História concisa da literatura brasileira, no restrito espaço que reserva à obra de Caminha, Bosi diz que "não se deve [...] reduzir o escritor do Ceará ao tributo que manifestamente pagou à leitura de Eça de Queirós e Aluísio Azevedo, seus modelos mais próximos" (BOSI, 1981: 216-7). Entretanto, no apertado parágrafo que dedica a Bom Crioulo, ao mesmo tempo em que se refere ao acerto na concepção literária do protagonista do romance, Bosi evita mencionar o tema da obra, preferindo referir-se muito enviesadamente ao argumento de Bom Crioulo, dessa maneira privilegiando explicar, um tanto à la século XIX, uma suposta sintomatologia de Amaro, cuja "passionalidade" o moveria "pelos meandros do sadomasoquismo, à perversão e ao crime". Assim, o historiador literário esquiva-se de assinalar aquilo que deveras caracteriza a obra no contexto da literatura brasileira, isto é, o fato de que Bom Crioulo é o primeiro romance escrito no Brasil que trata frontalmente e, como disse, com relativa imparcialidade, do tema da homossexualidade.

Nesse momento, já estamos, não é demasiado dizê-lo, diante de uma obnubilação de tipo ideológico. Tudo passaria como se, na república das letras brasileiras, algumas de suas mais reconhecidas inteligências necessitassem encontrar um pretexto para explicar a exclusão de Adolfo Caminha de seu merecido lugar, sem mencionar a mais provável razão para que isso se tivesse dado - ao incômodo, ou ainda ao que poderia ser considerado o preconceito, da crítica acadêmica para com o tema "desviante". Miguel-Pereira ao menos diz que ele é "extremadamente chocante" - isto é, em poucas palavras, reconhece o que acaba de ser dito. Por sua vez, Bosi singelamente o silencia.

Aqui cabe assinalar a terceira surpresa: tudo funcionaria como se a crítica brasileira - que, como expoente do sistema literário, tanto se orgulha de cantar os avanços reais, estéticos e ideológicos da literatura nacional em face do cânone ocidental moderno - não pudesse encontrar em Bom Crioulo um motivo mais de afiançamento da sua qualidade e da sua fortaleza. Se ninguém discute a excelência das respostas engenhosas e de alto nível estético que os literatos encontraram, ao longo da história do Brasil independente, para enfrentar, de forma original e autônoma, certas situações ou correntes estéticas internacionais - como, por exemplo, no caso do modernismo dos anos 1920 , 
só para citar o mais paradigmático desses momentos -, não pode deixar de nos surpreender que, em relação a Bom Crioulo, tudo passa, em termos acadêmicos, como se nada tivesse passado. Ou, melhor dito, tudo passa como se a literatura brasileira pudesse prescindir de um romance inovador como foi Bom Crioulo, e de um autor capaz, apesar de sua pouca idade e de sua minguada e desigual produção literária (Caminha morreu em 1897, aos trinta anos incompletos, deixando numerosos inéditos), de desenvolver um tema tabu, e de forma tão independente. Finalmente, tudo quiçá tenha passado como passou, sinceramente em nome dos bons costumes.

Como assinalei antes, não foi senão recentemente que a fortuna de Adolfo Caminha mudou, e isso não devido a leituras originadas na academia, porém, à margem dela. Na verdade, e de forma muito característica, pode-se dizer que isso se deu de fora para dentro: foi a partir da edição norte-americana de Bom Crioulo - intitulada The Black Man and the Cabin Boy, publicada pela Gay Sunshine Press de São Francisco, em 1982, em tradução de E. A. Lacey - que o romance e seu autor passaram efetivamente a ter direito de cidadania, ao menos ao exterior da academia brasileira. Em si mesmo, esse dado poderia, no contexto do presente ensaio, aparecer como uma nova, e irônica, "surpresa"; entretanto, a verdade é que, no restrito círculo de leitores independentes, especialmente ao longo dos anos 1970 - e mais especialmente ainda, entre os letrados homossexuais que por aquela década ensaiavam no Brasil os primeiros passos para a criação de uma memória ou uma consciência gay nacionais -, já Bom Crioulo gozava de certo cachet, que o silêncio dos media sobre uma reedição do romance em 1976, em plena ditadura militar, devido ou não a ingerências da censura, não fez mais do que intensificar. Sem dúvida, a isso corresponde, forçoso é dizê-lo, o fato de que o tradutor e os editores americanos tenham topado com a obra.

Numa primeira leitura contemporânea de Bom Crioulo escrita no Brasil, o romancista João Silvério Trevisan, em seu estudo sociológico sobre a história da homossexualidade em terras brasileiras, Devassos no Paraíso, analisando o desenvolvimento do enredo de Bom Crioulo, no qual Aleixo abandona Amaro pelos exuberantes amores de uma portuguesa vinte anos mais velha do que ele, classifica a obra da seguinte forma:

[...] O resultado é quase uma ópera Carmen às avessas, inclusive com todos os empolamentos melodramáticos; talvez por isso tenha permanecido não só legí- 
vel mas encantadoramente moderno, mais de um século depois. Poucas vezes a literatura brasileira produziu uma obra tão corajosa e direta sobre amores proibidos. Num Brasil provinciano, recém-entrado na República, Caminha trata o amor com surpreendente naturalidade, como um dado específico e irrefutável, chegando até mesmo a criar uma legítima ternura entre dois homens do povo. (TREVISAN, 1986: 152)

Entretanto, devemos ao tradutor E. A. Lacey um esboço mais completo, e talvez mais definitivo, do alcance de Bom Crioulo. No "Prefácio do Tradutor" da edição estadunidense, Lacey diz:

Bom Crioulo was - and remains - a truly revolutionary work: revolutionary in its denunciation of slavery, sadism, cruelty and man's exploitation of man; revolutionary in its revelation of society's complicity, its conspiracy of silence, regarding all these abuses; revolutionary in its startling attitudes toward homosexuality, toward race, toward interracial and inter-age contacts. (LACEY, 1982: 20-1)

Mais adiante nesse prefácio, referindo-se um tanto apaixonadamente à triste saga de Amaro, que termina por assassinar seu amado Aleixo num rompante de ciúmes que revela sua desadaptação social global, Lacey sumariza o valor da personagem engendrada por Caminha:

[...] the story of the black slave who dared to dream of love, freedom and a world beyond race, sex and age, and learned too late that society would grant him none of these, only betrayal, imprisonment and discrimination, should be read and remembered. (LACEY, 1982: 20-1)

Como não poderia deixar de ser, em função da "obnubilação programada" preexistente, uma obra com as características de Bom Crioulo deixou de ser uma ilustre ausência nas letras brasileiras e passou ao status de simbolizar uma espécie de cultural icon, desfraldado para o regozijo de minorias interessadas em fazer valer seu peso específico na formação da "casa completa" das letras nacionais. O que não deixa de ser, por explicável que seja essa démarche, algo surpreendente: Adolfo Caminha, cuja condição heterossexual está acima de qualquer suspeita - aliás, foram os seus amores com uma mulher casada de 
boa família que o distanciaram dos escritores contemporâneos no Ceará e, de passagem, levaram-no à sua exclusão da Marinha Imperial -, ele mesmo se surpreenderia, quiçá, com os valores imputados à sua obra, a cento e tal anos da sua publicação.

Entretanto, no circuito dos intelectuais homossexuais militantes, apesar da provável surpresa do seu autor, Bom Crioulo goza atualmente de plena saúde: Luis Zapata, o tradutor mexicano da obra, por exemplo, faz eco à sua contraparte americana, e lhe atribui foros de primazia, no contexto internacional, ao dizer que a originalidade de Bom Crioulo supera a de Escal-Vigor, do escritor flamengo Georges Eekhoud, publicada em 1899, considerada pelo estudioso da temática homoerótica na literatura Jacques Brenner como o primeiro romance que aborda o tema da homossexualidade na literatura ocidental. ${ }^{4}$ Bom Crioulo, aquele romance ignorado pelos críticos responsáveis pelo desenho geral de nossa literatura, seria um chef-de-file internacional: uma obra que, pela sua idiossincrasia - como o Frankenstein de Mary Shelley ou as Die Wablverwandtschaften, "As afinidades eletivas", de Goethe, segundo E. A. Lacey -, prenunciaria alguns lineamentos da literatura contemporânea.

Evidentemente, isso poderia funcionar como um alerta aos acadêmicos brasileiros, ou aos de qualquer parte: estavam diante de um pudim - e não o puderam degustar, ou não souberam como fazê-lo. O que parecia epigonal não o era senão superficialmente: se a ênfase na análise literária tivesse se voltado não às características mais restritamente textuais do relato, mas à sua verdadeira literariedade, e para lá do horizonte ideológico-moral da leitura, Bom Crioulo a esta altura seria parte do próprio cânone da literatura brasileira e da língua portuguesa, e não seguiria sendo estudado - quando o é - como um fenômeno de exceção. A cento e tantos anos de sua publicação, em função de tudo o que disse anteriormente, não nos cabe mais que homenagear essa surpreendente obra.

4 ZAPATA, Luis. "Prólogo" à tradução mexicana de Bom Crioulo (México: Posada, 1987, 2. ed., p. 16). Mais adiante em seu "Prólogo", Zapata resume sua apreciação sobre esse romance da seguinte maneira: "[...] una de las mayores virtudes de Bom Crioulo consiste en algo que Caminha logró descubrir o intuir: los homosexuales no son estereotipados; nada más lejos de la figura lánguida y refinada de las personajes proustianas; nada más lejos de los hispersensibles e inteligentes protagonistas de las novelas de Forster y Gide; nada más lejos de los 'jotos' del cine mexicano sesentero, que el negro Amaro, Bom Crioulo: borracho, parrandero y jugador, pero también ingenuo, generoso, tierno, enloquecido por el amor". 
Mas regressemos agora a O Barão de Lavos. Abel Botelho, que foi alguma vez - e muito erroneamente, nunca é demais dizê-lo - assinalado como um precursor de Adolfo Caminha, e isso por razões de ordem exclusivamente cronológica, encarnou, sim, todos os lugares-comuns em relação à homossexualidade que a ética do século XIX preconizava. O "patólogo” português talvez não fizesse por mal: sua preocupação era a degeneração que produz a história, especialmente quando o protagonismo nela vê-se restrito a uma classe fechada, como a aristocracia portuguesa, como Massaud Moysés, afinado com a mentalidade do próprio Botelho, chamou atenção no trecho anteriormente mencionado. Porém, ao autor (ou o crítico) como "patólogo", como autoridade paramédica, e tratando o mesmo humanissíssimo universo, Caminha ofereceu uma alternativa: o autor como narrador, simplesmente. Ao discurso cientificizante, Caminha contrapôs, sem pretendê-lo talvez, o humano. Amaro não é, em essência, o Barão de Lavos, e sua sorte, assim como sua economia literária, não poderia ser a mesma.

Preocupado com a verdade e não com a exemplaridade do que narra - o que portanto o distancia da ideologia de interpretação do narrado -, Caminha encontra o fato em si, e não aquele que seria digno de uma qualquer arquitetura narrativa, exemplar de tudo o que devesse ela ser para melhor proveito social e moral da coletividade que a desfruta. Sua aceitação da realidade, sua relativização da ideologia dominante é, para todos os efeitos, aquilo que o singulariza e o dignifica entre todos os naturalistas, dentro ou fora do âmbito brasileiro; exatamente por isso, Bom Crioulo, inspirada por, e embebida na realidade objetiva, constitui uma obra liberada e mesmo contestatária das constrições escolares da ética-estética que, in nuce, a informaram.

Ao contrário de O Barão de Lavos, no contexto da literatura portuguesa, o lugar de Bom Crioulo no devir da literatura brasileira, se tomarmos a preconceituosa hermeneusis que a crítica literária acadêmica tentou fazer dela, é, visto desde a pós-modernidade, simplesmente desconstrutivo. Qualquer perfil ideal da literatura brasileira parece desvanecer-se em contato com o seu frescor sempre renovado; se isto não estava no programa hermenêutico da inteligência crítica brasileira de meados do século XX, tant-pis. Tal é o poder do fato literário quando considerado em sua totalidade, para lá dos limites traçados por uma inteligência crítica homogeneizadora e, não será demais afirmá-lo, carola.

Hoje, a vivacidade de uma literatura mede-se por suas complexidades e contradições - parafraseio o título daquele que foi talvez o mais importante 
livro para o estabelecimento de uma razão, ou una sensibilidade, pós-moderna, Complexity and Contradiction in Architecture, de Robert Venturi (1974). Por que seriam a literatura brasileira, ou a portuguesa for that matter, duas das tantas atuantes no mutável cenário cultural contemporâneo, algo diferente? A partir de qual delírio de onipotência poderia considerar a crítica literária o ser capaz de reduzir a mesma literatura a uma qualquer arquitetura que excluísse as manifestações literárias mais difíceis ou problematicamente classificáveis?

A história da fortuna crítica de Bom Crioulo parece atribuir a esse romance uma posição central no que concerne à(s) resposta(s) às perguntas formuladas, no contexto brasileiro ou mesmo no da língua literária que se escreve em português. Obra cuja originalidade - e problematicidade - está hoje mais viva do que nunca, e encontra-se plantada no horizonte mais radical da literatura menos adjetivável.

\section{Referências Bibliográficas}

BOSI, Alfredo. História Concisa da Literatura Brasileira. 3. ed. São Paulo, 1981. p. 216217.

LACEY, E. A. Translator's Preface. In: CAMINHA, Adolfo. The Black Man and the Cabin Boy. p. 20-21.

MIGUEL PEREIRA, Lúcia. História da Literatura Brasileira Prosa de Ficção - de 1870 a 1920. Rio de Janeiro: José Olympio, 1950.

MOYSÉS, Massaud. A "Patologia Social" de Abel Botelho. São Paulo: Faculdade de Filosofia, Letras e Ciências Humanas da Universidade de São Paulo, 1961.

TREVISAN, João Silvério. Devassos no Paraíso. 2. ed. São Paulo: Record, 2000.

VENTURI, Robert. Complejidad y contradicción en la arquitectura. Barcelona: Gustavo Gili, 1974. 